\title{
Dynamic Stability Improvement of Power System with VSC-HVDC Transmission
}

\author{
R. Vasudevan ${ }^{1^{*}}$, S. Ramalakshmi ${ }^{2}$ \\ ${ }^{1}$ PG Scholar, Department of Electrical and Electronics Engineering, Prist University, Thanjavur, Tamilnadu, India. \\ ${ }^{2}$ M.E, Assistant Professor, Department of Electrical and Electronics Engineering, Prist University, Thanjavur, Tamilnadu, India. \\ *Corresponding author E-mail:vaasu2666@yahoo.com
}

\begin{abstract}
A new management approach for the reactive-power injections of Voltage supply Converters in High Voltage DC (VSC-HVDC) multiterminal Systems to enhance grid transient stability. A reactive-power supplementary signal is provided for each convertor. Its worth is proportional to the frequency deviation of its consequent $\mathrm{AC}$ bus with admiration to the weighed-average frequency of the multiterminal system stations. The hope is to extend (decrease) the magnetism torsion of generators close to those terminals during which the frequency is superior to (below) the weighed-average frequency used. The AC frequency for all VSC stations is ever more accessible regionally for synchronization functions and will be utilized by a central controller. Simulations are allotted victimization PSS/E and therefore the outcome have revealed that transient stability is enlarged victimization this approach. Since this approach uses world capability of all VSC stations, the collision of the communication delays has been analyzed, concluding that the depressing consequence is modest, for realistic latency values.
\end{abstract}

Keywords: VSC HVDC, HVDC transmission, multiterminal, transient stability, reactive power, power systems

\section{Introduction}

Development of High Voltage Direct Current (HVDC) technology has brought to considering a meshed Multi-terminal Direct Current (MTDC) network into prospect power system planning. As the power systems are becoming more consistent and power production more decentralized, MTDC seems as a solution for power transfer over large distances and increasing security of supply. On the other hand, they require scaling up power systems, and higher in feed of power impending from renewable energy sources, resulted in a higher require for control reserve. Control reserve is defined as methods for maintenance the balance connecting shaped and consumed electrical power, even in the case of rigorous disturbances. The goal of this master's opinion was to find a solution for negligible power reserve activation, in systems that contain MTDC networks. The development of high voltage direct current (HVDC) links offer an option solution for the capable and flexible transmission of electrical energy that can maintain the future power system beside recurrent dimensions. These assumptions revise the control of HVDC injections in power systems during energetic scenarios. Coordinated HVDC control has a outsized potential for the energetic performance of power systems, for occasion by growing the damp of power oscillations, but is at present not conquered in a systematic way. The aim is to expand a framework for power system organizes through HVDC transmission links. Starting with results for conformist AC networks, the argument presents power system models, procedure approaches and network development methods in the situation of dynamically controlled HVDC links. The modeling of power systems with HVDC links has to incorporate quite a few physical and operational constraints compulsory by the HVDC links and the surrounding AC network. A description of the resulting constraints on the HVDC injections is meticulous significant if the HVDC links are to be worn for energetic power system control.

\section{Related Works}

In [1] Jef Beerten, Stijn Cole, and Ronnie Belmans et al presents the calculation of electromechanical permanence models of voltage source converter towering voltage direct current (VSC HVDC) to multi-terminal (MTDC) systems. The document initiate a categorize reproduction with a cascaded DC voltage control at each converter that tolerate a two-terminal VSC HVDC format to handle with converter outages. When widespread to an MTDC system, the models obviously evolve into a master-slave set-up with converters captivating over the DC voltage control in case the DC voltage controlling converter fails. It is shown that the replica can be used to comprise a voltage droop control to share the power disparity after a contingency in the DC system surrounded by the converters in the system. Finally, the commentaries discuss two credible model reductions, in line with the supposition made in transient stability modeling.

In [2] Stijn Cole, Jef Beerten, and Ronnie Belmans et al present a novel general voltage source converter high voltage direct current (VSC MTDC) model is ensuing precisely. The full system model consists of the converter and its controllers, DC circuit equations, and coupling equations. The main donation of the new model is it's valid for every possible topology of the DC circuit.

Practical implementation of the model in power system stability software is discussed in feature. The generalized DC equations can all be articulated in terms of matrices that are byproducts of the construction of the DC bus admittance matrix. Initialization, switching actions resulting in dissimilar topologies and 
reproduction of the loss of DC lines quantity to a simple calculation or recalculation of the DC bus admittance matrix.

In [3] Javier Renedo, Aurelio Garc'sa-Cerrada, Luis Rouco et al presents Multi-terminal High Voltage electricity (HVDC) exploitation Voltage supply Converters (VSC-HVDC) could be a proficient technology that provides versatile management of active and reactive power and facilitates remote renewable energy integration, in particular exploitation long cables. This paper analysis a vigorous power management approach for multiterminal VSC-HVDC systems tailored to boost transient stability of hybrid AC/DC grids. The planned strategy controls every VSC exploitation frequency measurements of all terminals. Its performance is compare to a technique during which every VSC is controlled exploitation solely native frequency measurements of the AC side; prove that the planned strategy shows higher performance, even taking under consideration wise announcement delays.

In [4] Robert Eriksson et al presents the stability of an interconnected ac/dc system is affected by disturbances occurring in the system. Disturbances, such as three-phase faults, may endanger the rotor-angle constancy and, thus, the generator fall out of synchronism. The possibility of fast change of the injected powers by the multi terminal dc grid can, by proper control action, enhance this stability. This paper proposes a novel time best control approach for the injected power of multi terminal dc grids to enhance the rotor-angle stability. The controller is time optimal, since it reduces the impact of a disturbance as fast as possible, and is based on Lyapunov theory considering the nonlinear behavior. In [5] Alexander Fuchs, Markus Imhof, Manfred Morari et al presents The stabilization of bulky power systems using voltagesource-converter-based elevated voltage direct current (HVDC) links. Based on global power system measurements, a model predictive control (MPC) scheme control the power injections of the HVDC links to damp oscillations in the ac system. Different scenarios like the defeat of production, the loss of consumption and changes to the network topology are purposeful in the continental European Network of Transmission System Operators for Electricity (ENTSO-E) system. The simulations show the presentation increase get with a worldwide MPC-based grid controller; compare to a limited damping controller and HVDC links with constant direction values.

\section{Proposed System}

A coordinated management move toward for the reactive-power injections of the converters of associate degree MTDC system victimization, only, the frequencies measured at the VSC stations (already accessible for synchronization). The results can show that, with this approach, the crucial Clearing Times (CCTs) will be augmented extensively. World approach was given with superior leads to once scheming active power in an MTDC theme.

\section{Block diagram}

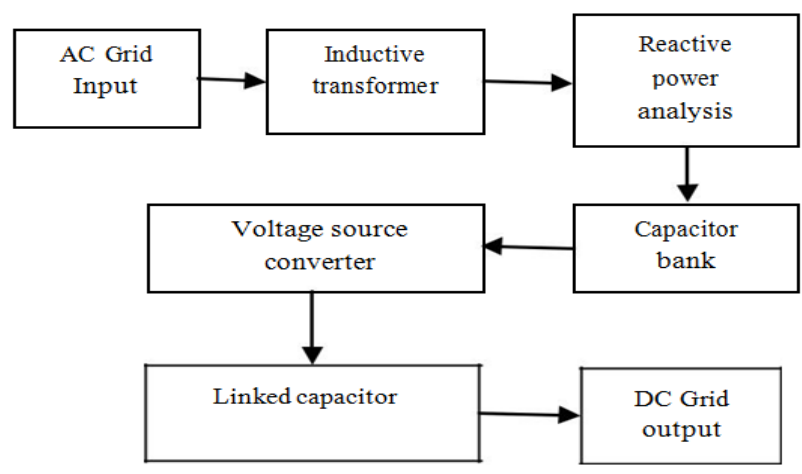

Fig. 1: Block diagram

\section{HVDC Technology}

Even though there is an vast integer of applications in dissimilar countries LCC knowledge have show significant weakness. The commutation of the converter valves is closely associated to the stiffness of the ac voltage at the grid connection point. For that reason, the converter does operate properly at connection points with low short circuit power. The reason is that the LCC cannot create ac voltage itself. It is always necessary for the operation of the LCC that the system provides the necessary voltage. Another difficulty for the case of LCC-HVDC system is that reactive power compensation is needed. Significant amount of shunt reactive power compensation and harmonic filters are required for operation. This makes the substations large, occupying big area making LCC impractical for very compact sites. In addition, the application of LCC is incomplete to one direction current flow through each converter. Hence, in order to reverse the power flow of any individual terminal the dc voltage polarity must be upturned as well. This is the major reason why LCC based HVDC technology cannot be used in applications such as multiterminal offshore HVDC networks. In a multi-terminal dc system which applies LCC technology, changing the division of the dc voltage for one dc line will modify the power flows in the network.

\section{VSC Terminal Model}

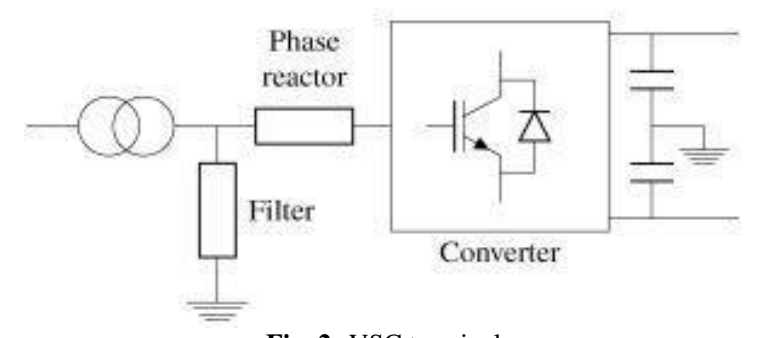

Fig. 2: VSC terminal

The physical classification of a VSC-HVDC consists of a transformer on the AC side of the converter, filter, a complex inductance, VSC, a HVDC cable and an inverter on the other side of the cable. By remove the filter the calculation of converter-side voltage and power flows is simplified. Filter is important if the VSC is using reactive power for its operation. In the case of LineCommutated HVDC the commutation is possible only with lagging current and therefore it requirements reactive power. At high powers they require for unthinking power grows as well. Therefore the AC side filter is used not only for filtering purposes but also as a reactive power compensator.

\section{VSC-HVDC Components}

In order to value the in commission opinion of VSC-HVDC it is significant to appreciate the components that such a system consists of. Figure demonstrates a typical VSC-HVDC system with converters, phase reactors, transformers, DC capacitors, AC filters and DC cables. These components will be describe in more detail in the subsequent sections 


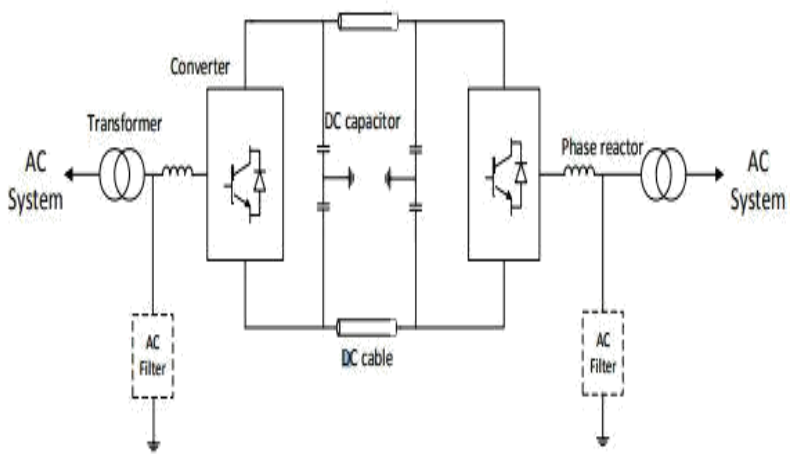

Fig. 3: VSC-HVDC components

The converter is the most important component of the VSCHVDC system and it is used to transfer power from the AC side to the DC side when operating as a rectifier, or to inject power into the AC side operating as an inverter. It uses Pulse Width Modulation (PWM) to generate the desired voltage waveform. In this thesis, Sinusoidal Pulse Width Modulation (SPWM) is considered where the basic principle is to compare a sinusoidal control voltage to a triangular wave, also called a carrier wave.

\section{VSC-HVDC Technology}

The solution to the above problem is given by the operation of the more recent version of HVDC technology known as the voltage source converter based high voltage direct current technology (VSC-HVDC). The development of VSC technology is based both on the improved performance and the increasing rating of the insulated gate bipolar transistors (IGBT). Also important role plays the controllability that IGBTs illustrate by means of capability to turn on and off and thus becoming a self commutated rather than line commutated converter. Furthermore, sinusoidal pulse width modulation technique (SPWM) gives flexibility and improves the performance of operation generating less harmonic distortion with the introduction of the VSC-HVDC, there's no got to modification the dc voltage polarity so as to vary the dc power flows, because it is that the case of LCC technology. The last characteristic is extremely enticing for implementation of the VSC-HVDC at offshore dc networks. What is more, there's no would like for reactive power compensation and no got to install giant filters to suppress harmonic distortion. As a result, the convertor station of VSC-HVDC is additional compact compared to the LCC technology with useful effects on the development of compact and versatile offshore station. Last however not least, with VSC-HVDC it's potential to bear stage development of meshed ac-dc networks, with quick and price economical designing, construction and authorization

\section{Principle of VSC-HVDC}

In principle, each VSC-HVDC converter is talented to manage active and reactive power separately by simultaneously modifiable the amplitude and phase approach of the fundamental component of the converter output voltage. The general control scheme of one VSC-HVDC converter station is shown in the Fig

The control functions of VSC-HVDC system can be classified by three control layers: system control layer, application control layer, and converter control layer as shown in Table I. The system layer controller establishes the functions for achieving bulk electric grid objectives such as power flow control, congestion management and voltage support.

\section{Active-Power Control Strategies}

The active-power (P) injections of the converters in MTDC systems should be coordinated so as to realize the required in operation purpose and (b) to regulate the DC voltage of the HVDC grid. The DC-voltage of Associate in Nursing MTDC system will be controlled by just one device, the "DC slack", or this roll will be distributed between collections of converters, employing a "DC-voltage droop" strategy. [16] The latter choice appears to be additional applicable in massive HVDC grids. The active-power point of every device $i$, with the DC-voltage droop controller and an extra supplementary reference will be written as:

$$
p_{s, i}^{r e f}(t)=p_{s, i}^{0}-\frac{1}{k_{d c, i}}\left(u_{d c, i}^{0}-u_{d c, i}^{t}(t)\right)+\Delta p_{s, i}^{r e f}(t)
$$

\section{Reactive-Power Control Strategies}

In MTDC systems, the reactive-power (Q) injections of the converters will be controlled severally. The converters will organization their $\mathrm{Q}$ injections or AC-voltages to constant values or, equally to the active-power management, supplementary set points will be enclosed within the outer management loop to produce accessory services. During this work, Q supplementary controllers for transient stability improvement are studied. The Q point of device $i$, together with its supplement, will be written as:

$$
q_{s, i}^{\operatorname{ref}}(t)=q_{s, i}^{0}+\Delta q_{s, i}^{\text {ref }}(t)
$$

\section{VSC-MTDC System}

Depending on the aim of the study, DC cables is shapely with distributed model or with $\pi$-circuit model. The distributed model is appropriate for transient analysis, whereas the $\pi$ circuit model is employed for slower dynamics. For applying the projected management methodologies during this thesis, the $\pi$ circuit model is chosen and also the quick active because of the inductances of the DC cables and also the switching's of the converters don't seem to be thought-about during this study. The shunt DC condenser put in every DC bus is additionally enclosed within the condenser of the $\pi$-circuit model. Converters area unit to blame for injecting active power to MTDC system or extracting power from it. Completely different modeling approaches area unit bestowed within the literature. 2 models are used for the aim of this thesis. Within the initial model, solely the dynamic of the DC grid is taken into account and also the power exchange between AC and DC area unit depicted by DC current sources.

\section{Output Result}

\section{HVDC-VSC Input}

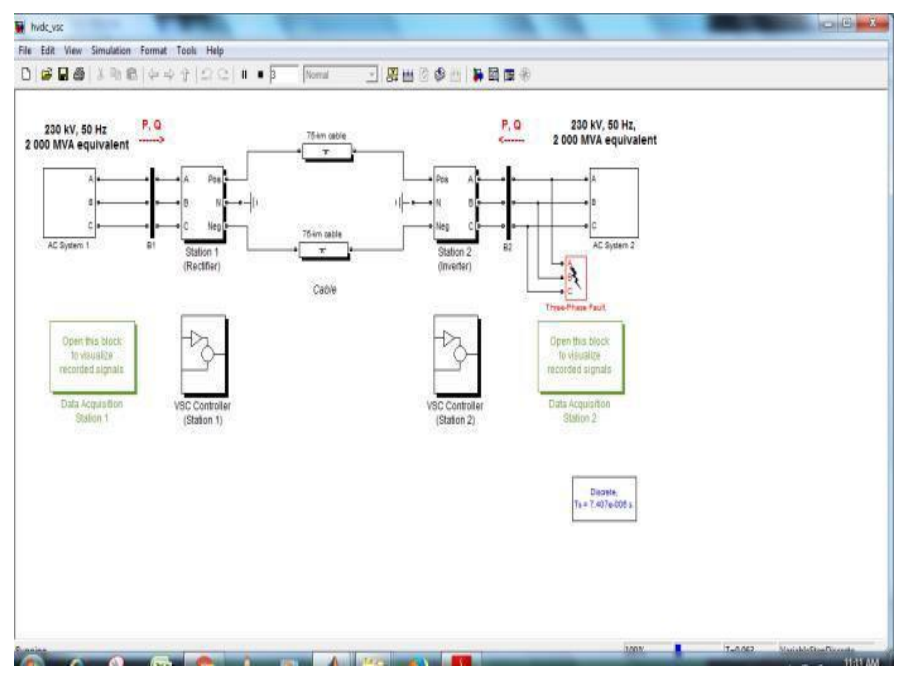




\section{Model 1}

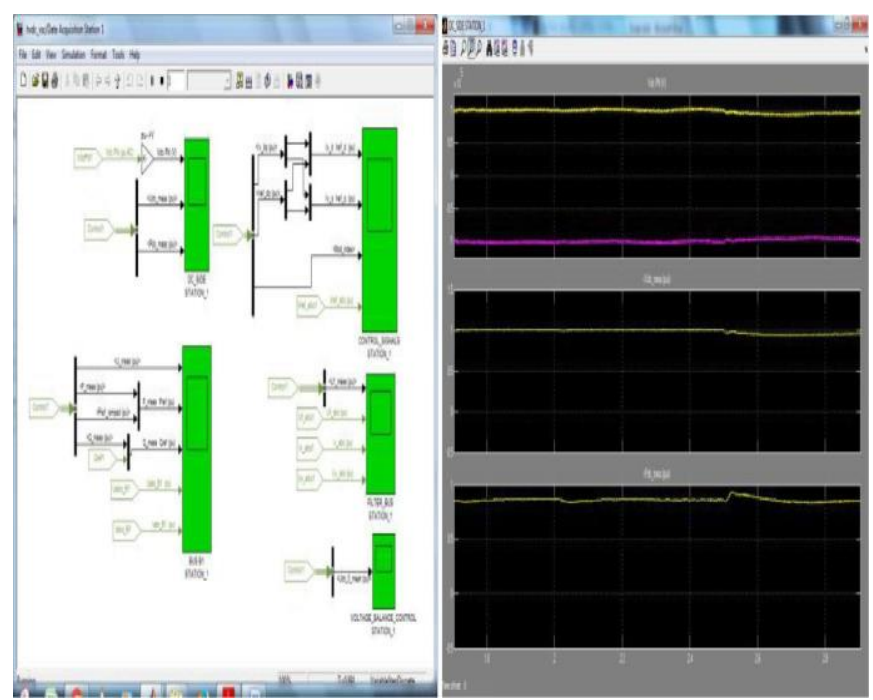

\section{Transient Stability Model and Filter Output}

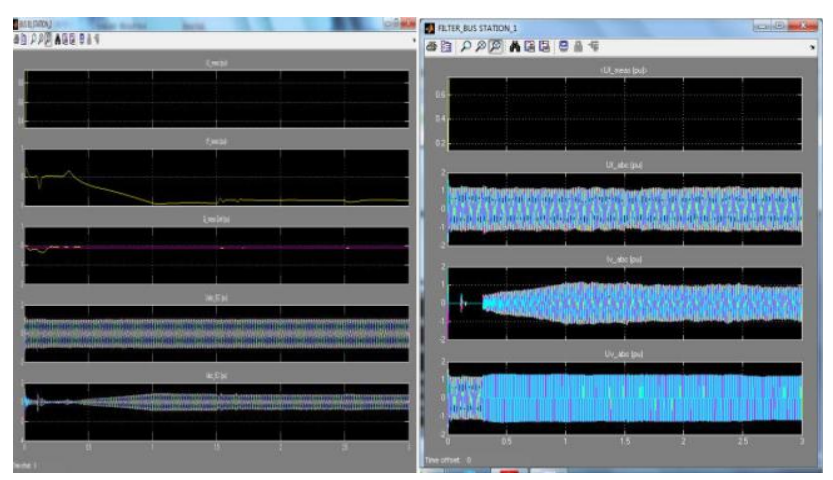

\section{Conclusion}

A reactive-power management strategy of a VSCHVDC multiterminal system for transient stability improvement in power systems has been projected and analyzed. It consists in a very proportional management theme that uses the weighted-average frequency at the MTDC system converters because the frequency set-point worth. Every VSC station would inject (absorb) reactive power if the frequency at its terminals is higher than (below) the reference worth. The paper includes full description of the proposal, a simplified theoretical analysis employing a Lyapunov equation operate and detail simulation, victimization PSS/E, with many situations supported the Nordic 32A system with a 3terminal MTDC system inbuilt. All told cases the soundness limit has been measured victimization the CCT. 1st of all, differentseverity faults are investigated. Secondly, the result of the outage of 1 of the converters within the system has been analyzed. Thirdly, the performance of the system in AN N-2 case of the first grid has been studied. The projected management strategy has been compared with (a) no action from the MTDC system and (b) modulation primarily based solely on native frequency measurements, wherever communication between the device stations isn't necessary. All told cases, the projected strategy will increase CCTs (transient stability is improved) and outperforms the opposite ways.

\section{References}

[1] Bompard E, Fulli G, Ardelean M \& Masera M, "It's a Bird, It's a Plane, It's a...Supergrid", IEEE power \& energy magazine, Vol.12, No.2, (2014), pp.41-50.

[2] Van Hertem D \& Ghandhari M, "Multi-terminal VSC HVDC for the European supergrid: Obstacles", Renewable and Sustainable Energy Reviews, Vol.14, No.9, (2010), pp.3156-3163.

[3] Kundur P, Power System Stability and Control, McGraw Hill Education, (1993).

[4] Haque MH \& Kumkratug P, "Application of Lyapunov stability criterion to determine the control strategy of a STATCOM", IEE Proc. Gener. Transm. Distrib., Vol.151, No.3, (2004), pp.415-420.

[5] Haque MH, "Improvement of First Swing Stability Limit by Utilizing Full Benefit of Shunt FACTS Devices", IEEE Transactions on Power Systems, Vol.19, No.4, (2004), pp.18941902.

[6] Abido MA, "Power system enhancement using FACTS controllers: A review", The Arabian Journal for Science and Engineering, Vol.34, No.1B, (2009), pp.153-172.

[7] Taylor CW, Mechenbier JR \& Matthews CE, "Transient Excitation Boosting at Grand Coulee Third Power Plant: Power System Application and Field Tests", IEEE Transactions on Power systems, Vol.8, No.3, (1993), pp.1291-1298.

[8] D'1ez-Maroto L, "Improvement of Voltage Ride Through Capability of Synchronous Generators with Supplementary Excitation Controllers", Master thesis, Universidad Pontificia Comillas, (2013).

[9] Zhou Y, Huang H, Xu Z, Hua W, Yang F \& Liu S, "Widearea measurement system-based transient excitation boosting control to improve power system transient stability", IET Generation, Transmission \& Distribution, Vol.9, No.9, (2015), pp.845-854.

[10] Fuchs A, Imhof M, Demiray T \& Morari M, "Stabilization of Large Power Systems Using VSC HVDC and Model Predictive Control", IEEE Transactions on Power Systems, Vol.29, No.1, (2014), pp.480-488.

[11] Sanz M, Chaudhuri B \& Strbac G, "Coordinated Corrective Control for Transient Stability Enhancement in Future Great Britain Transmission System", 19th PSCC Genoa, (2016), pp. 1-7.

[12] Sigrist, L Echavarren F, Rouco L \& Panciatici P, "A fundamental study on the impact of HVDC lines on transient stability of power systems", PowerTech Eindhoven, (2015).

[13] Machowski J, Kacejko P, Nogal L \& Wancerz M, "Power system stability enhancement by WAMS-based supplementary control of multiterminal HVDC networks", Control Engineering Practice, Vol.21, No.5, (2013), pp.583-592.

[14] Eriksson R, "Coordinated Control of Multiterminal DC Grid Power Injections for Improved Rotor-Angle Stability Based on Lyapunov Theory", IEEE Transactions on Power Delivery, Vol.29, No.4, (2014), pp.1789-1797.

[15] Tang G, Xu Z, Dong H \& Xu Q, "Sliding Mode Robust Control Based Active-Power Modulation of Multi-Terminal HVDC Transmissions", IEEE Transactions on Power Systems, Vol.31, No.2, (2016), pp.1614-1623.

[16] G, Abikhanova, A Ahmetbekova, E Bayat, A Donbaeva, G Burkitbay (2018). International motifs and plots in the Kazakh epics in China (on the materials of the Kazakh epics in China), Opción, Año 33, No. 85. 20-43. 